\title{
EXTRUSION OF AN INHALED FOREIGN BODY THROUGH THE CHEST WALI
}

\author{
RoberT S. Monro, F.R.C.S. \\ Consultant Surgeon, Ipswich and East Suffolk Hospital
}

Small children are given to putting inedible objects into their mouths, whence they are not uncommonly inhaled into the respiratory tree, becoming impacted in a bronchus and setting up unpleasant secondary septic complications. Once beyond the larynx it is unusual for such objects to be coughed up spontaneously, and as a rule they have to be removed by bronchoscopy or by thoracotomy and bronchotomy or even by lobectomy (Robinson and Mushin, 1956). It is very unusual for such objects to be extruded spontaneously through the chest wall and a search of the literature covering the last ten years reveals only two references to such an event, both reported from Russia (Belenkaya, I953; and Aliev, 1958). The present contribution gives an account of the spontaneous extrusion of an inhaled grass-head through a child's chest-wall.

\section{Case History}

A small boy aged 3 was admitted to the Ipswich and East Suffolk Hospital on June 25, 1958, with an I I-day history of cough and rapid breathing. At the onset of his illness he had been sick a number of times and had appeared to keep constantly clearing his throat and had refused food altogether for several days. He was an illegitimate child in a neglected and dirty state, looking ill and unhappy. He was febrile, temperature $103.6^{\circ} \mathrm{F}$., pulse rate 150 , respiratory rate $5^{6}$ per minute.

On clinical examination there was evidence of consolidation in the right chest, and of a right lower lobe pneumonia. Chest X-ray showed a pleural effusion and consolidation in the right lower lobe with a wedge-shaped consolidated area anteriorly, which was interpreted either as an area of collapse, or in view of the apparent raising of the inter-lobar septum, as an area of inter-lobar effusion (Figs. I and 2).

Treatment was commenced with crystalline penicillin I million units initially, and subsequently 250,000 units six-hourly. The pyrexia subsided, the child's condition improving, and penicillin was discontinued on June 29. The dullness at the्ठ right base, however, appeared to be increasing, 3 indicating an increasing effusion and on the following day a soft tissue tumour, which was redo and tender, appeared in the subcutaneous tissues of $\vec{\overrightarrow{ }}$ the right chest postero-inferiorly, leading to $\mathrm{a} \overrightarrow{\mathrm{c}}$ tentative diagnosis of empyema necessitatis. The child, however, by now seemed really too fit for ${ }^{\circ}$ such a major septic complication, and as the main ${ }_{c}^{-}$ radiological indications of pleural effusion appeared to be anteriorly, while the swelling on the chest wall was posteriorly, the possibility of az subperiosteal osteomyelitis of rib was also $\operatorname{cog}-\overrightarrow{0}$ sidered, and the swelling was aspirated. On+yㅇㅇ 3 c.c. of moderately thick cream-coloured pus wefe obtained and were replaced with I million units affo penicillin. Systemic penicillin was resumed. A smear of the pus showed scanty gram-positive cocci and culture showed strepto coccus viridans $\frac{\mathrm{O}}{\mathrm{Q}}$ sensitive to penicillin. The swelling, however, $\stackrel{\varrho}{\Rightarrow}$ gradually recurred, the child remaining remarkably fit all the while, and the abscess was explored on July 7 , one week later. A small quantity of watery pus was released and a remarkable finding? made. Several fragments of a large whiskered윽 grass-head were discovered lying in a small:subcutaneous cavity, their butt ends pointing downwards and forwards with a suggestion of a deep intercostal sinus posteriorly and superiorly. $\frac{0}{3}$ There was, however, no patent communication remaining with the pleural cavity (Fig. 3). The grass-heads were removed and the wound sutured $\frac{D}{5}$ with drainage. The child made an uninterrupted recovery, the physical signs in his chest resolving N rapidly.

On direct questioning, the child's mother sub- N sequently recalled that two weeks prior to his ${ }_{\sigma}^{\omega}$ admission to hospital he had swallowed a large

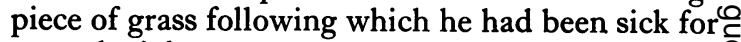
several nights.

\section{Comment}

From this history it would appear that the child $\stackrel{\overrightarrow{\mathbb{D}}}{\mathrm{D}}$ 

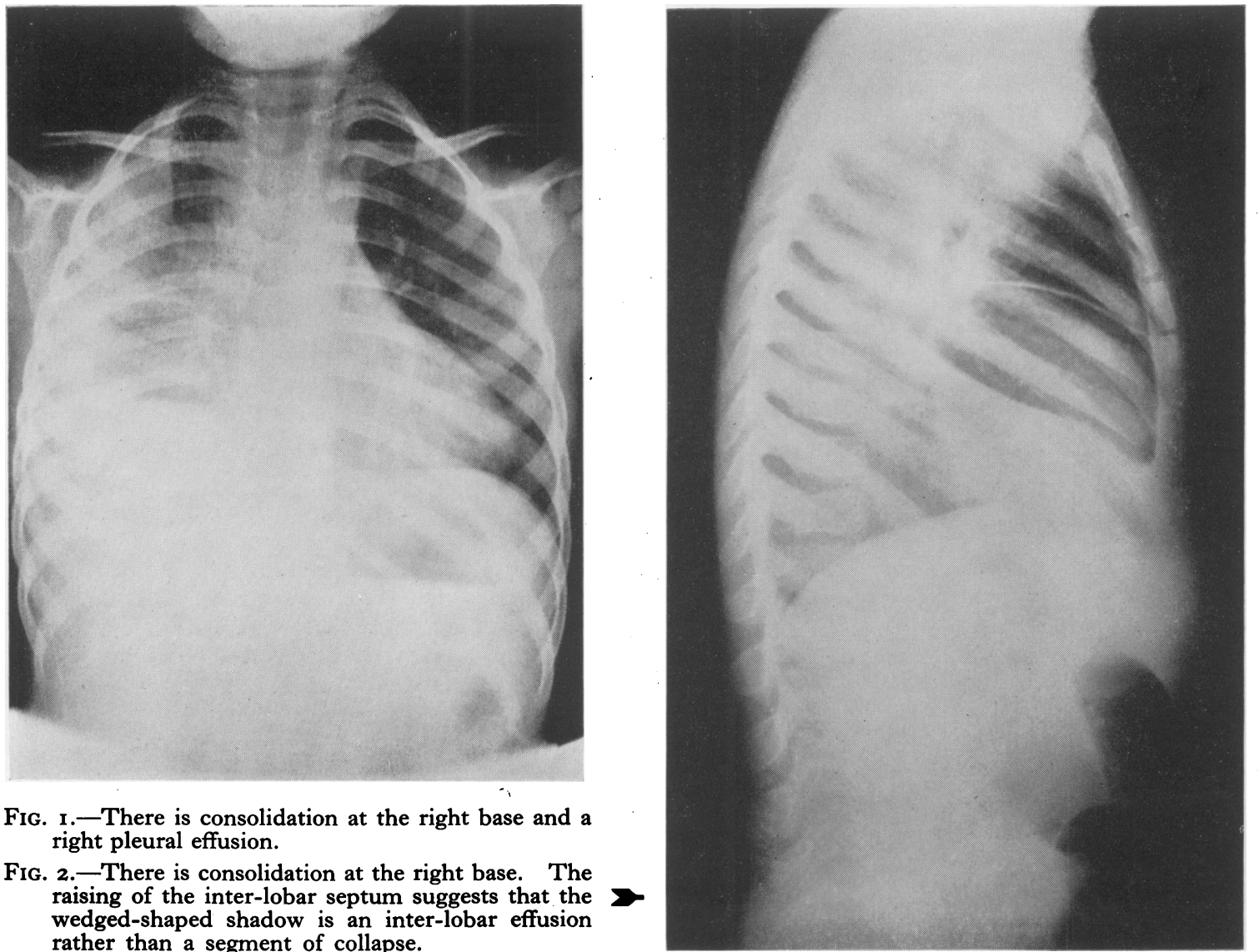

Fig. I.-There is consolidation at the right base and a right pleural effusion.

Fig. 2.-There is consolidation at the right base. The raising of the inter-lobar septum suggests that the wedged-shaped shadow is an inter-lobar effusion rather than a segment of collapse.

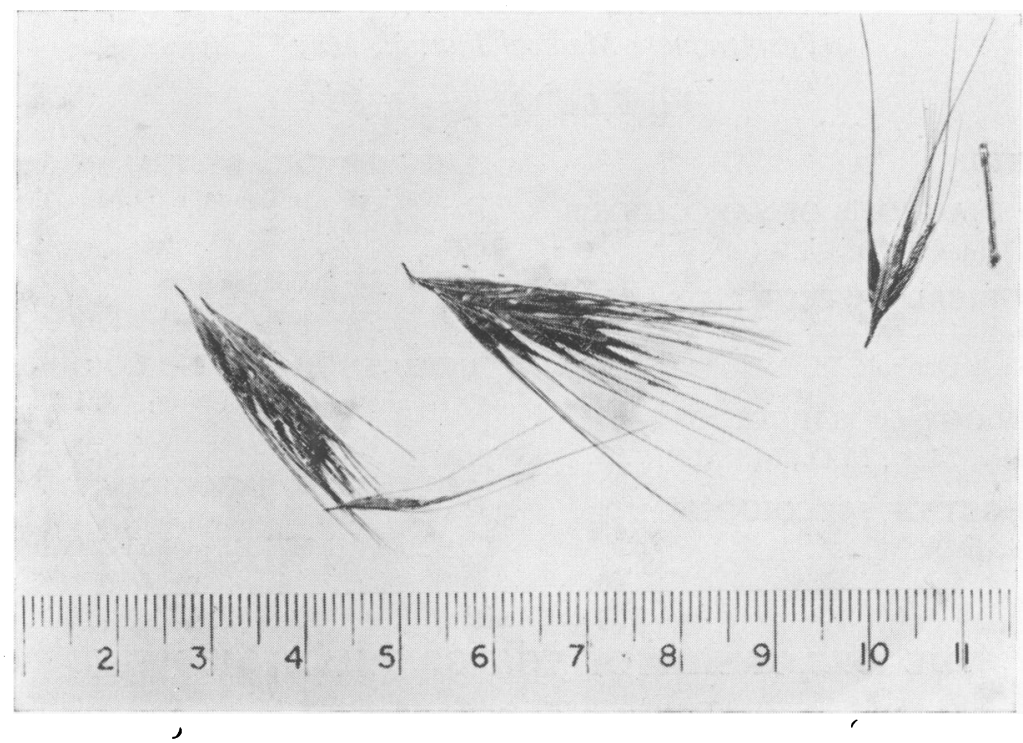

FIG. 3.-Grass-head of Hordeum murinum (Wall Barley) removed from subcutaneous abscess of chest wall. 
swallowed a grass-head which became lodged in all probability in his pharynx or laryngeal aditus, causing the initial vomiting and coughing and attempts to clear his throat. Subsequently, propelled by its spiny awns it must have migrated down his trachea into his right lower lobe bronchus, producing pneumonia and consolidation, and then migrated through the lung substance and through visceral and parietal pleura, which were presumably adherent over the area of maximal inflammation, though separated in other areas by the radiologically recognisable pleural effusion. Finally the grass-head must have traversed the intercostal space to reach the subcutaneous position in which it was found.

The grass-head is a specimen of Hordeum murinum L., or Wall Barley. It flourishes on poor soil, in particular on soil where the sub-soil has been brought to the surface by building operation and on waste land near walls and buildings. The specific name murinum, meaning mouselike, refer to the characteristic tendency for the heads of this grass to creep, propelled by their long serrated. awns. Every country boy must have played witk the heads of barley grass, allowing them to migrate in various parts of his clothing, but few childre can have experienced such a drastic and unusuaf migration as occurred in this case.

My thanks are due to Mr. and Mrs. Johes Dickson for their help in identifying the grasshead and for supplying me with botanical information.

\section{REFERENCES}

ALIEV, B. M. (1958), Klin. med. (Moskva), 36, 103. BELENKAYA, R. S. (1953), Pediatriya, (Moskva), r, 60. ROBINSON, C. L. N., and MUSHIN, W. W. (1956), Brit. med. $\mathcal{F} ., 2,324$.

\section{SARCOIDOSIS}

(Postgraduate Medical Journal, May 1958)

Price 6s. 6d. post free

\section{INTRODUCTION}

THE EARLY DIAGNOSIS OF SARCOIDOSIS

D. Geraint James, M.D., M.R.C.P.

THE HISTORICAL ASPECTS OF SARCOIDOSIS

Professor Niels Danbolt, M.D.

THE PATHOLOGY OF SARCOIDOSIS

A. D. Thomas, M.A., M.D., M.R.C.P.

THE AETIOLOGY OF SARCOIDOSIS

Louis E. Siltzbach, M.D.
THE NERVOUS SYSTEM IN SARCOIDOSIS

Michael Jefferson, D.M., M.A., B.Sc., M.R.C.P.

\section{BERYLLIUM DISEASE}

I. B. Sneddon, M.B., Ch.B., F.R.C.P.

INTRATHORACIC SARCOIDOSIS

Kenneth M. Citron, M.D., M.R.C.P., M.R.C.S.

\section{CUTANEOUS SARCOIDOSIS}

Gordon B. Mitchell-Heggs, M.D., F.R.C.P., and Michael Feiwel, M.B., Ch.B., M.R.C.P.

Published by

THE FELLOWSHIP OF POSTGRADUATE MEDICINE

60, Portland Place, London, W.1 